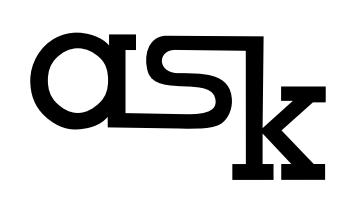

Research \& Methods

ISSN 1234-9224, e-ISSN 2544-0799

Vol. 28 (1, 2019): 43-59

The Ohio State University Libraries

Columbus, Ohio, USA

Institute of Philosophy and Sociology

Polish Academy of Sciences, Warsaw, Poland

www.askresearchandmethods.org

https://doi.org/10.18061/ask.v28i1.0003

\title{
Explaining the Policy Constraints of Anti-democratic Regimes by Means of Sequential OLS-Regressions
}

\author{
Georg P. Mueller \\ University of Fribourg
}

\begin{abstract}
One of the key problems of many sociological regression models is their modest explanatory power. This has not only to do with the insufficient development of the underlying theories but also with the free will of the concerned social actors, which manifests itself in irrational, spontaneous, and sometimes even arbitrary decisions. The foreign and economic policy of the US government under Donald Trump is an excellent example of this source of indeterminacy.

An alternative and more promising approach is an explanation of the constraints of social behaviour by the unequal distribution of power resources and the competing interests of the actors concerned. This approach requires, on the one hand, enough observational data which include cases that reached the analysed constraints. On the other hand, there is a need for statistical procedures which estimate and explain these constraints. Assuming that sufficient amounts of data are available, this paper proposes the use of sequential OLS regressions, which eliminate step by step non-critical observations in order to identify the cases that reached the mentioned constraints.

For illustrative purposes, the author analyses the policy space of anti-democratic regimes with regard to their possibilities of curbing democracy. On the basis of the democracy scores of Freedom House, the author explores the governmental constraints set by (i) national civil societies and (ii) international NGOs for the promotion of political/ civil rights. The related sequential regressions allow for an assessment of how effective the different constraints are and how far democracy may deteriorate in the worst case under given structural conditions.
\end{abstract}

Key words: Policy constraints, OLS regression, International comparisons, Democratisation, Anti-democratic regimes. 


\section{INTRODUCTION AND OVERVIEW}

Regression models of social or economic behaviour are often based on unrealistic assumptions about the rationality and the emotional stability of the actors which they intend to describe. They yield regression lines and ex-post predictions, which typically neglect the actors' free will, emotionality, and spontaneous shifts in preferences (Earman 1986: chap. 12). This problem is especially critical for analyses which are not focused on statistically aggregated behaviour of groups, but rather on decisions of particular actors. Consequently, these analyses often have only limited explanatory power (see e.g. Hibbs (1973: chap. 6) about the behaviour of political elites). Moreover, they are generally hard to cross-validate with data from similar samples, which is currently discussed as the so-called replication crisis of the social sciences (Hughes 2018: chap. 1; Schmidt 2017).

In view of this unsatisfactory situation, the present article promotes an alternative approach: it proposes to analyse possible instead of real decisionmaking behaviour. In this article, possible behaviour is assumed to be constrained by the power and the interests of other actors. This assumption promises ex-post forecasts, which are more reliable and robust because they depend not only on the arbitrary plans of one but of several actors with contradictory interests. Moreover, it adds to the explanation of social behaviour by teleological/final causation (Stout 1996: chap. 3; Schueler 2003: chap. 3) another important element: constraints by the power and will of others, which make for the analysed actor certain forms of behaviour impossible (Mueller 2012). It is obvious that this approach also requires new statistical techniques in order to estimate the mentioned behavioural constraints from the available observational data. For this purpose, we propose in this article a sequential regression procedure which excludes step by step all observations that are not sufficiently close to the analyzed constraint-line (see section 3, Fig. 3). At the end of this elimination process the only observations remaining are those which represent the focused constraint and these can consequently be used to identify it.

In order to illustrate this constraint-approach as well as its methodological implications, the article analyses the policy space of governments with regard to the curbing of democratic freedom, which is described by time series of the political rights index (PR) of Freedom House (2017) for ca. 180 countries and territories. Two types of constraints of this policy space are considered: political protests of the national civil society and trade or consumer boycotts organized or induced by international NGOs. Both constraints together define the governmental policy space, which can be used for forecasts about future democratic freedom. The two constraints may, however, also be compared with regard to their relative importance. The related empirical analyses reveal that neither are very effective, especially if the political rights of the civil society are already restricted by an 
authoritarian government. However, civil society is generally more important than international NGOs, except in countries with strongly authoritarian regimes and high trade dependency, for which our empirical analyses show that international NGOs are more effective than civil society.

\section{A MODEL OF THE GOVERNMENTAL POLICY SPACE: THE CASE OF POLITICAL FREEDOM}

This article is based on the hypothesis that democracy is a universal value, which triggers the expectations of many actors, hoping for increased political freedom in terms of popular participation in the political decision-making process. One of these collective actors is the national civil society, which is directly concerned by any change of its political system. Its weapons for defending democracy are political protests, votes for or against the ruling government, etc. Another important actor is the international community of NGOs, which aims at promoting democracy and human rights on a global scale, e.g. by inducing economic sanctions by the UN, international trade boycotts, etc. This second, international group includes Freedom House, Human Rights Watch, Amnesty International, etc.

The expectation $\mathrm{E}_{\mathrm{i}}$ of any of these groups $\mathrm{i}$ with regard to the political freedom $\mathrm{F}_{+}$at a future point in time is assumed to be guided by the following three principles, which together represent our hypothesis 1:

a) If the current political freedom $\mathrm{F}$ is at the lowest possible level $\mathrm{F}=\mathrm{F}_{\text {min }}$, the group i expects an increase of freedom by a positive basic expectation $b_{i}$. Thus

$$
\text { If } \mathrm{F}=\mathrm{F}_{\min } \rightarrow \mathrm{E}_{\mathrm{i}}=\mathrm{F}_{\text {min }}+\mathrm{b}_{\mathrm{i}}
$$

where $b_{i}>0$

b) If the current political freedom $F$ is at the highest possible level $F=F_{\max }$, the expectations of group i are already fulfilled, since freedom cannot be increased anymore. Thus

$$
\text { If } \mathrm{F}=\mathrm{F}_{\text {max }} \rightarrow \mathrm{E}_{\mathrm{i}}=\mathrm{F}_{\text {max }}
$$

c) All other cases are treated by linear interpolation between situations (a) and (b). Thus

$$
\mathrm{E}_{\mathrm{i}}=\mathrm{F}+\Delta
$$

where $\Delta=\mathrm{b}_{\mathrm{i}} *\left(\mathrm{~F}_{\text {max }}-\mathrm{F}\right) /\left(\mathrm{F}_{\text {max }}-\mathrm{F}_{\text {min }}\right)$ 
As Fig. 1 demonstrates, the expectation $\mathrm{E}_{\mathrm{i}}$ about the future freedom $\mathrm{F}_{+}$increases with the current level of freedom $F$, whereas the gap $\Delta$ between $F$ and the expectation $\mathrm{E}_{\mathrm{i}}$ decreases with the current level of freedom $\mathrm{F}$.

In principle, the level of future freedom $\mathrm{F}_{+}$can deviate by a factor $D_{i}$ from the expectation $\mathrm{E}_{\mathrm{i}}$ of a group I; however, only as much as the tolerance $T_{i}$ of the group with regard to the violation of its interests permits. Hence, we postulate as hypothesis 2:

$$
D_{i}=\left(E_{i}-F_{+}\right) / E_{i} \leq T_{i} \text {, for all groups i }
$$

Thus, there are possible choices of freedom $\mathrm{F}_{+}$and impossible ones. The latter would create so many deprivations (Gurr 2010: chap. 2) that government risks revolutionary violence (Davies 1972) or harsh international trade sanctions (Cleveland 2015). It is important to note that for possible choices all inequalities of equation (2) must be fulfilled. Hence, each group has a "veto" against the choice of $F_{+}$if it violates its expectations $\mathrm{E}_{\mathrm{i}}$ in an intolerable way. This motivates the research interest in identifying the most important among the different groups, which represents the critical constraint of the governmental policy space. The answer to this question depends on the relative effectiveness of the different groups in defending their expectations, which has to be explored by empirical analyses (see section 6).

Regarding the tolerance $T_{i}$, there are many different factors, like political traditions, authoritarian culture, etc., which could be taken into consideration.

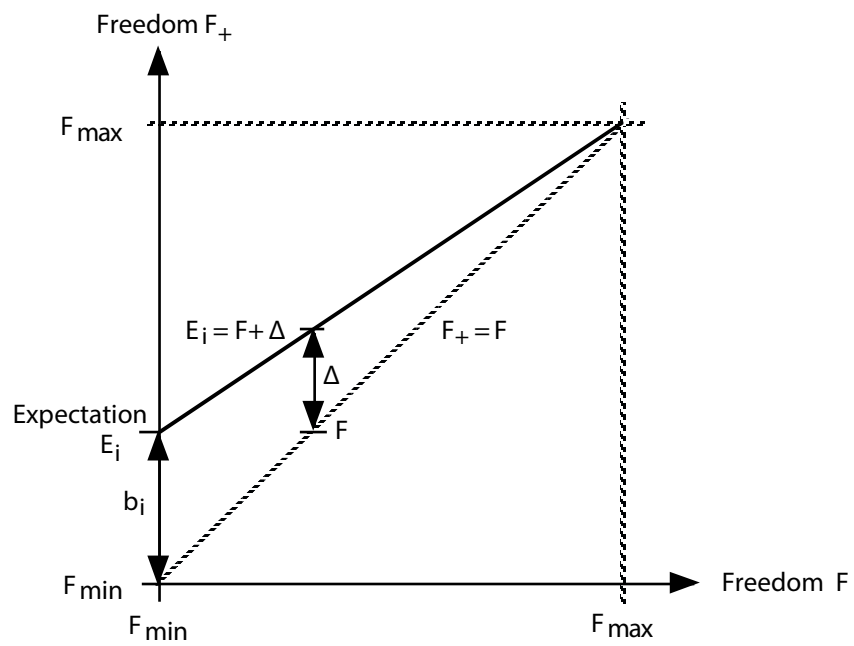

Fig. 1: The hypothetical relation between the current polit. freedom $\mathrm{F}$ and the expectation $E_{i}$ about the polit. freedom $F_{+}$at a future point in time 
However, for analysing which of the governmental policies are really possible, the most important of these factors is, according to section 1, the political power $P_{i}$ that can be used by the group $i$ against a governmental decision: the more power $\mathrm{P}_{\mathrm{i}}$ the group i has, the smaller its tolerance for deviance from its expectations. Thus, we postulate as hypothesis 3 :

$$
\mathrm{T}_{\mathrm{i}}=\mathrm{k}_{\mathrm{i}}+\mathrm{c}_{\mathrm{i}} * \mathrm{P}_{\mathrm{i}},
$$

where $\mathrm{k}_{\mathrm{i}}>0$ and $\mathrm{c}_{\mathrm{i}}<0$

The combination of the equations (2) and (3) yields the condition for possible choices of the future freedom $\mathrm{F}_{+}$:

$$
\mathrm{D}_{\mathrm{i}}=\left(\mathrm{E}_{\mathrm{i}}-\mathrm{F}_{+}\right) / \mathrm{E}_{\mathrm{i}} \leq \mathrm{k}_{\mathrm{i}}+\mathrm{c}_{\mathrm{i}} * \mathrm{P}_{\mathrm{i}}=\mathrm{T}_{\mathrm{i}}
$$

If condition (4) is violated, the related decision about $\mathrm{F}_{+}$is impossible, as indicated in Fig. 2. Thus, there is a constraint $C_{i}$ for possible decisions about $F_{+}$, which can be derived from equation (4) ${ }^{1)}$ and leads to the following hypothesis 4 :

$$
\mathrm{C}_{\mathrm{i}}=\mathrm{E}_{\mathrm{i}} *\left(1-\mathrm{k}_{\mathrm{i}}-\mathrm{c}_{\mathrm{i}} * \mathrm{P}_{\mathrm{i}}\right) \leq \mathrm{F}_{+}
$$

Since $c_{i}<0$, the constraint line $\mathrm{C}_{\mathrm{i}}$ increases with the power Pi and, consequently, narrows the governmental policy space of possible decisions if the group i becomes more powerful (see Fig. 2).

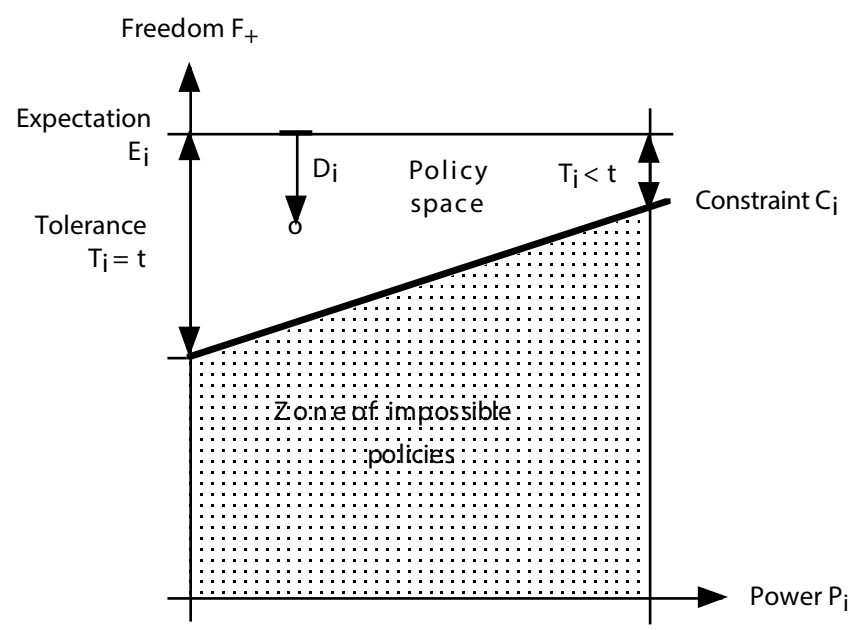

Fig. 2: The hypothetical relations between the power $P_{i}$, the tolerance $T_{i}$, and the resulting constraint $C_{i}$ 


\section{OPERATIONALISATIONS AND ESTIMATIONS FOR TESTING THE MODEL}

For empirical tests of the previous hypotheses $1-4$, most of the theoretical concepts of section 2 have to be measured or estimated for two groups of actors $i$, i.e. the national civil society ( $\mathrm{i}=$ nat) and the international community of NGOs ( $\mathrm{i}$ = int), which aim at promoting democracy.

The most important variables to be operationalised are freedom $F$ and $F_{+}$. We are using for this purpose the political rights index $P R$ of Freedom House (2017). ${ }^{2)}$ It is a complex democracy index ${ }^{3)}$, which is often cited by $\mathrm{UN}$-agencies and the World Bank (Giannone 2010: 75-76) as well as the daily news media. Nonetheless, for this article the index PR has two major drawbacks: first, in the short run it doesn't change too much and second, it has a polarity which is the reverse of political freedom. Thus, we focused on a 5-year interval with more change and inverted its polarity such that

$$
\begin{aligned}
& \mathrm{F}=\mathrm{F} \_2011=8-(\text { Polit. Rights } \mathrm{PR} \text { in 2011) } \\
& \mathrm{F}_{+}=\mathrm{F}_{-} 2016=8-(\text { Polit. Rights PR in 2016) }
\end{aligned}
$$

From the definitions of the original PR-indicators it follows that $\mathrm{F}_{\text {min }}=1$ and $\mathrm{F}_{\max }=7$.

The measurement of the expectations $E_{i}=E_{\text {nat }}$ and $E_{i}=E_{\text {int }}$ is much more difficult. According to the equations (1a-c), they depend on one single parameter, i.e. the basic expectation $b_{i}$. Thus, we used different working hypotheses about possible values of $b_{i}$ and finally selected the one with the best fit $r^{2}$ between the theoretical and the real tolerance for deviance $T_{i}$ (see Fig. 3). In this way we achieved the best possible statistical estimate of $E_{i}$ and implicitly determined the values of the deviances

$$
\mathrm{D}_{\mathrm{i}}=\left(\mathrm{E}_{\mathrm{i}}-\mathrm{F}_{+}\right) / \mathrm{E}_{\mathrm{i}}
$$

As postulated by hypothesis 3 , the maximum possible deviance $\mathrm{T}_{\mathrm{i}}$ depends on the power $P_{i}$ of the national civil society ( $\mathrm{i}=$ nat) and the international community of NGOs (i=int), which also had to be operationalised in order to enable empirical tests. The power of the international NGOs over the government of a particular target country is very much influenced by its trade dependency. The more dependent the country is on international trade, the more vulnerable it is to boycotts, either organised by governments or consumer movements (Hufbauer et al. 2009: 62). Thus, we operationalised the power 
Georg P. Mueller, Explaining the Policy Constraints of Anti-democratic Regimes by

$$
\mathrm{P}_{\text {int }}=100 *(\text { Foreign trade in 2011) / (GDP in 2011) }=\text { TradeDep_2011 }
$$

by making use of the trade dependency data which the World Bank (2019) has published for the year 2011.

The power of the national civil society in relation to its government is mainly influenced by its political rights. The more political rights, the better the chances of forcing a government out of office, e.g. by democratic elections or massive political protest (Hibbs 1973: 112). Thus, we operationalised the power

$$
\mathrm{P}_{\text {nat }}=\text { F_2011 }=8 \text { - (Polit. Rights PR in 2011) }
$$

where PR is the political rights index of Freedom House (2017).

According to equations (3) and (4), the deviance $\mathrm{D}_{\mathrm{i}}$ is limited by the tolerance $T_{i}$ such that the following inequality holds for both groups, i.e. $i=$ nat and $i=i n t$ :

$$
\mathrm{D}_{\mathrm{i}} \leq \mathrm{T}_{\mathrm{i}}=\mathrm{k}_{\mathrm{i}}+\mathrm{c}_{\mathrm{i}} * \mathrm{P}_{\mathrm{i}}
$$

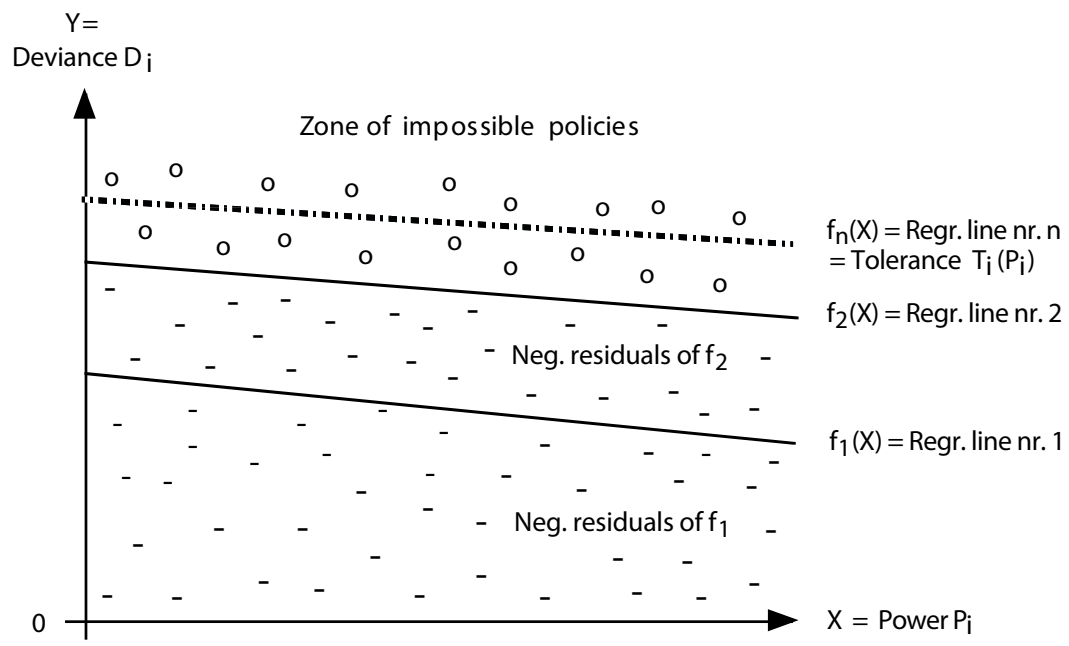

Legend: Dependent variable: Deviance $D_{i}$; Independent variable: Power $P_{i}$; Sample for $f_{1}$ : all $D_{i} \geq 0$; Sample for $f_{2}$ : all $D_{i}$, excl. neg. residuals of $f_{1}$; Sample for $f_{3}$ : all $D_{i}$, excl. neg. residuals of $f_{1}$ and $f_{2}$; Sample for $f_{n}$ : all $D_{i}$, excl. neg. residuals of $f_{1}, \ldots, f_{n-1}$.

Fig. 3: The estimation of the tolerance for deviance $T_{i}$ and the related parameters $k_{i}$ and $c_{i}$ by successive linear regressions. 
Assuming that $b_{i}, E_{i}, D_{i}$, and $P_{i}$ are all known, either by measurement or plausible working hypotheses, the tolerance $T_{i}$ and the related parameters $k_{i}$ and $\mathrm{c}_{\mathrm{i}}$ could be estimated by the following iterative process, which is visualised in Fig. 3 and described in an earlier article by the author (Mueller 2012: 82). It is a special form of the iteratively reweighted least squares technique (Rubin 1983; Andersen 2008: $52 \mathrm{ff}$.) and starts with a conventional OLS regression, where $\mathrm{Y}=$ $\mathrm{D}_{\mathrm{i}}$ is the dependent and $\mathrm{X}=\mathrm{P}_{\mathrm{i}}$ the independent variable. Since we are interested in violations of expectations, $Y$ is restricted to cases where $D_{i} \geq 0$. After removing the non-critical observations below the regression line $\mathrm{f}_{1}(\mathrm{X})$ with negative residuals, the remaining data are used for a second regression analysis ${ }^{4}$, which yields the regression line $f_{2}(X)$. Since we are mainly interested in the highest possible deviances $D_{i}$ for a given value $X=P_{i}$, we have to remove all cases with negative residuals below the line $f_{2}(X)$. By repeating this process of estimating regression lines $f_{j}(X)$ and subsequently removing the related negative residuals, the process finally converges to the upper margin of the data cloud, which corresponds to the tolerance $T_{i}$. It is recommended that this process is stopped after a rather limited number of $\mathrm{n}$ regressions such that the final regression equation $\mathrm{f}_{\mathrm{n}}(\mathrm{X})$ is calculated with ca. $10 \%$ of the original data points. In this way ca. $10 \% / 2=5 \%{ }^{5}$ of all $\mathrm{D}_{\mathrm{i}}$ are in so far "rare" observations as they are beyond the limit $\mathrm{T}_{\mathrm{i}}$. As mentioned earlier, this regression procedure can be repeated for different working hypotheses about the basic expectation $b_{i}$ and the associated $E_{i}$ and $D_{i}$. By choosing the $b_{i}$ with the best final $\mathrm{r}^{2}$, sequential regression also yielded estimates for $\mathrm{E}_{\mathrm{i}}$ (see eqns. (1a-c)) and $\mathrm{D}_{\mathrm{i}}$ (see eqn. (7)).

\section{THE ESTIMATION OF THE NATIONAL CONSTRAINTS}

By means of the previous sequential regression procedure it is possible to estimate the tolerance $\mathrm{T}_{\text {nat }}$ (see hypothesis 3 ) of the national civil society

$$
\mathrm{T}_{\text {nat }}=\mathrm{k}_{\text {nat }}+\mathrm{c}_{\text {nat }} * \mathrm{P}_{\text {nat }}=\mathrm{k}_{\text {nat }}+\mathrm{c}_{\text {nat }} * \mathrm{~F}_{-} 2011,
$$

where $\mathrm{k}_{\text {nat }}>0$ and $\mathrm{c}_{\text {nat }}<0$

as well as the related constraint (see eqn. (5))

$$
\mathrm{C}_{\text {nat }}=\mathrm{E}_{\text {nat }} *\left(1-\mathrm{k}_{\text {nat }}-\mathrm{c}_{\text {nat }} * \mathrm{~F}_{-} 2011\right)
$$

We ran this estimation process for different plausible working hypotheses about the expectations $\mathrm{E}_{\text {nat }}$ and the associated parameter $\mathrm{b}_{\text {nat }}$, which were systematically varied between $b_{\text {nat }}=0$ and $b_{\text {nat }}=3$. Tab. 1 presents the best fitting results of these 
trials. By comparing the adjusted $\mathrm{r}^{2}$ of the final models $\mathrm{A} 4$, B4, and $\mathrm{C} 4$, it turns out that $\mathrm{b}_{\text {nat }}=2.00$ (see model B4) yields the best correspondence between model and data. Thus, for $\mathrm{F}_{-} 2011=\mathrm{F}_{\min }=1$, the national civil society expects an increase of freedom to $\mathrm{F}_{+}=\mathrm{F}_{\min }+2=3$ (see eqn. (1a)). Moreover, as hypothesised in equation (10), $\mathrm{k}_{\text {nat }}>0$ and $\mathrm{c}_{\mathrm{nat}}<0$ have the theoretically expected signs. They are statistically highly significant and consequently give the final model B4 a high explanatory power with an adjusted $\mathrm{r}^{2}=0.899$. The related Fig. 4 a seems to confirm the importance of the resulting constraint $\mathrm{C}_{\text {nat }}$. A comparison with Fig. $4 \mathrm{~b}$ illustrates the superiority of the presented approach of explaining the possible instead of the real governmental behaviour: Fig. 4b visualises for the same data cloud as Fig. $4 \mathrm{a}$ a conventional regression analysis with $\mathrm{b}_{\text {nat }}=2.00$, which corresponds to the model B1 of Tab. 1. However, the regression line of Fig. 4b has an explanatory power adj. $\mathrm{r}^{2}$ of only 0.718 instead of 0.899 (see Tab. 1) and displays the lower determinacy of the behavioural forecast, which is due to many high residuals that were intentionally excluded when calculating the model B4.

Tab. 1: Parameter estimation of the national tolerance for deviance $T_{\text {nat }}$

\begin{tabular}{|c|c|c|c|c|c|c|}
\hline $\begin{array}{l}\text { Sequential } \\
\text { model }\end{array}$ & $\begin{array}{c}\text { Basic } \\
\text { exp. } b_{\text {nat }}\end{array}$ & $\begin{array}{c}\text { Const. } \\
\mathrm{k}_{\text {nat }}\end{array}$ & $\begin{array}{c}\text { Coeff. } \\
c_{\text {nat }} \\
\end{array}$ & $\begin{array}{c}\mathrm{N} \\
\text { abs. }\end{array}$ & $\begin{array}{l}\mathrm{N} \\
\text { rel. }\end{array}$ & $\begin{array}{l}\text { Adj. } \\
\text { r-sq. }\end{array}$ \\
\hline $\mathrm{A} 1$ & 1.50 & $0.647^{* * *}$ & $-0.093^{* * *}$ & 176 & 1.000 & .725 \\
\hline A2 & 1.50 & $0.805^{\star * *}$ & $-0.110^{\star \star *}$ & 105 & 0.597 & .899 \\
\hline A3 & 1.50 & $0.903^{* * *}$ & $-0.109^{\star * *}$ & 34 & 0.193 & .826 \\
\hline$\underline{\mathrm{A} 4}$ & 1.50 & $\underline{0.921^{* * *}}$ & $\underline{-0.100^{* * *}}$ & $\underline{20}$ & $\underline{0.114}$ & .882 \\
\hline B1 & 2.00 & $0.694^{\star * *}$ & $-0.100^{\star * \star}$ & 184 & 1.000 & .718 \\
\hline B2 & 2.00 & $0.873^{* * *}$ & $-0.120^{\star * *}$ & 105 & 0.571 & .921 \\
\hline B3 & 2.00 & $0.953^{\star * *}$ & $-0.116^{\star \star \star}$ & 34 & 0.185 & .854 \\
\hline B4 & $\underline{2.00}$ & $\underline{0.969^{* * *}}$ & $\underline{-0.107^{\star * *}}$ & $\underline{20}$ & $\underline{0.109}$ & .899 \\
\hline C1 & 2.50 & $0.753^{\star \star *}$ & $-0.108^{\star \star *}$ & 185 & 1.000 & .761 \\
\hline $\mathrm{C} 2$ & 2.50 & $0.924^{\star * *}$ & $-0.127^{\star \star *}$ & 105 & 0.568 & .933 \\
\hline $\mathrm{C} 3$ & 2.50 & $0.993^{\star \star *}$ & $-0.121^{\star \star \star}$ & 34 & 0.184 & .874 \\
\hline$\underline{\mathrm{C} 4}$ & $\underline{2.50}$ & $\underline{0.932^{* * *}}$ & $\underline{-0.081^{* * *}}$ & $\underline{16}$ & $\underline{0.086}$ & .868 \\
\hline
\end{tabular}

Legend: Underlined: Final model for given $\mathrm{b}_{\text {nat }}$. Bold underlined: Best final model. One-tailed significances: ${ }^{* * *}$ : $p \leq .001,{ }^{* *}: p \leq .01,{ }^{*}: p \leq .05 . \mathrm{N}$ rel.: Relative sample size in comparison to the first model of a given $b_{\text {nat }}$. Adj. r-sq.: Adjusted $r$-square $=$ Fit of the model. Samples of the original models A1, B1, C1: Global full-samples, i.e. all countries and territories for which Freedom House (2017) has data. Dependent variable: $D_{i}$. Restriction Di $\geq 0$. Independent variable: $F \_2011$, which is sufficiently different from $D_{i}$ in order to avoid an autocorrelation (see eqns. (1c) and (7)). 


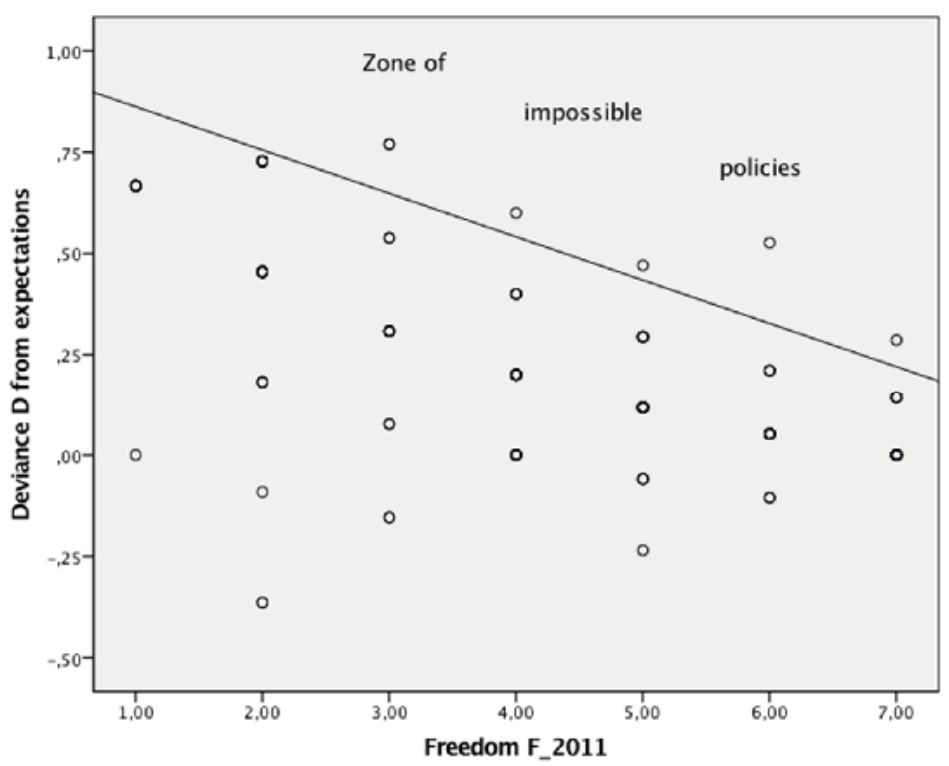

Fig. 4a: Explaining the constraint $C_{\text {nat }}$ of governmental behaviour by successive linear regressions ${ }^{6)}$

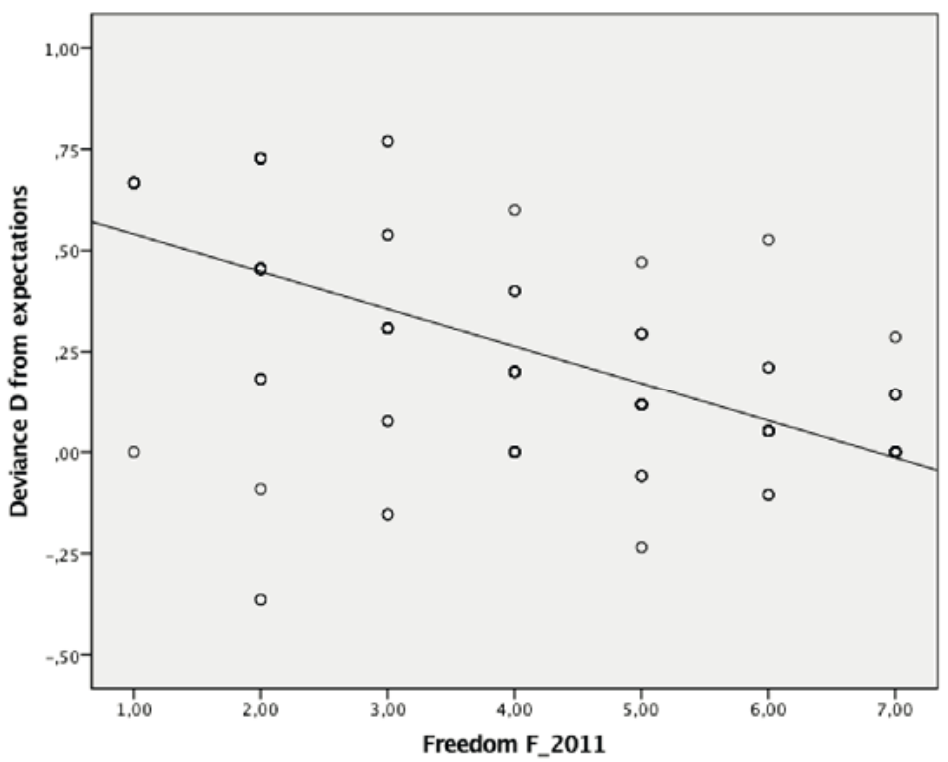

Fig. 4b: The classical approach: Explaining real governmental behaviour by ordinary linear regression ${ }^{6), 7)}$ 


\section{THE ESTIMATION OF THE INTERNATIONAL CONSTRAINTS}

For the community of international NGOs there are mathematical expressions similar to the equations (10) and (11), which describe the effect of the power $P_{\text {int }}$ of the international NGOs on their tolerance for deviance

$$
\begin{aligned}
& \mathrm{T}_{\mathrm{int}}=\mathrm{k}_{\mathrm{int}}+\mathrm{c}_{\mathrm{int}} * \mathrm{P}_{\mathrm{int}}=\mathrm{k}_{\mathrm{int}}+\mathrm{c}_{\mathrm{int}} * \text { TradeDep_2011, } \\
& \text { where } \mathrm{k}_{\mathrm{int}}>0 \text { and } \mathrm{c}_{\mathrm{int}}<0
\end{aligned}
$$

as well as on their related constraint

$$
\mathrm{C}_{\mathrm{int}}=\mathrm{E}_{\mathrm{int}} *\left(1-\mathrm{k}_{\mathrm{int}}-\mathrm{c}_{\mathrm{int}} *\right. \text { TradeDep_2011) }
$$

\begin{tabular}{|c|c|c|c|c|c|c|}
\hline $\begin{array}{l}\text { Sequential } \\
\text { model }\end{array}$ & $\begin{array}{c}\text { Basic } \\
\text { exp. } b_{\text {int }}\end{array}$ & $\begin{array}{c}\text { Const. } \\
\mathrm{k}_{\text {int }}\end{array}$ & $\begin{array}{c}\text { Coeff. } \\
\mathrm{C}_{\text {int }} \\
\end{array}$ & $\begin{array}{c}\mathrm{N} \\
\text { abs. }\end{array}$ & $\begin{array}{l}\mathrm{N} \\
\text { rel. }\end{array}$ & $\begin{array}{l}\text { Adj. } \\
\text { r-sq. }\end{array}$ \\
\hline A1 & 1.50 & $0.258^{\star * \star}$ & $-5.07^{*} 10^{-4}$ & 162 & 1.000 & .005 \\
\hline A2 & 1.50 & $0.531^{* \star *}$ & $-6.27^{*} 10^{-4}$ & 63 & 0.389 & .026 \\
\hline A3 & 1.50 & $0.652^{\star * \star}$ & $-3.07^{*} 10^{-4}$ & 31 & 0.191 & .001 \\
\hline$\underline{\mathrm{A} 4}$ & 1.50 & $\underline{0.723^{* * *}}$ & $\underline{-2.59^{*} 10^{-4}}$ & $\underline{12}$ & $\underline{0.074}$ & .147 \\
\hline B1 & 2.00 & $0.272^{\star * \star}$ & $-4.67^{*} 10^{-4}$ & 169 & 1.000 & .003 \\
\hline B2 & 2.00 & $0.586^{* * *}$ & $-7.40^{*} 10^{-4 *}$ & 64 & 0.379 & .040 \\
\hline B3 & 2.00 & $0.744^{\star * \star}$ & $-6.29 * 10^{-4 * *}$ & 28 & 0.166 & .211 \\
\hline B4 & $\underline{2.00}$ & $\underline{0.765^{\star \star *}}$ & $-4.31^{* 10^{-4}} \stackrel{* *}{-}$ & $\underline{14}$ & $\underline{0.083}$ & .463 \\
\hline C1 & 2.50 & $0.301^{* \star *}$ & $-5.28^{*} 10^{-4}$ & 170 & 1.000 & .004 \\
\hline C2 & 2.50 & $0.615^{\star * *}$ & $-8.10^{*} 10^{-4 *}$ & 68 & 0.400 & .042 \\
\hline C3 & 2.50 & $0.796^{\star \star \star}$ & $-8.58^{*} 10^{-4 * * *}$ & 29 & 0.171 & .320 \\
\hline$\underline{\mathrm{C} 4}$ & $\underline{2.50}$ & $\underline{0.779^{* * *}}$ & $\underline{-3.53 * 10^{-4}} \stackrel{* *}{-}$ & $\underline{18}$ & $\underline{0.106}$ & .339 \\
\hline
\end{tabular}

Tab. 2: Parameter estimation of the international tolerance for deviance $T_{\text {int }}$

Legend: Underlined: Final model for given $b_{\text {int }}$ Bold underlined: Best final model. One-tailed significances: ${ }^{* * *}: p \leq .001,{ }^{* *}: p \leq .01,{ }^{*}: p \leq .05 . \mathrm{N}$ rel.: Relative sample size in comparison to the first model for a given $b_{\text {int }}$ Adj. $r$-sq.: Adjusted $r$-square $=$ Fit of the model. Samples of the original models A1, B1, C1: Global full-samples, i.e. all countries and territories, for which Freedom House (2017) has data. Dependent variable: $D_{i}$. Restriction: $D_{i} \geq 0$. Independent variable: TradeDep_2011.

As in the previous section 4, sequential linear regression was used to estimate the parameters $\mathrm{k}_{\text {int }}$ and $\mathrm{c}_{\text {int }}$ for different working hypotheses about the basic expectation $b_{\text {int }}$, which was systematically varied between the plausible limits $b_{\text {int }}=0$ and $b_{\text {int }}=3$. The best statistical results are given in Tab. 2 and show the highest values of $r^{2}$ for 
the final model B4. Like in Tab. 1, the basic expectation $b_{\text {int }}=2.00$, implying that the international NGOs expect for $\mathrm{F} \_2011=\mathrm{F}_{\min }=1$ an increase of freedom to the level $\mathrm{F}_{\min }+2=3$ (see eqn. (1a)). For the optimal model B4, the parameters $\mathrm{k}_{\text {int }}$ and $\mathrm{c}_{\text {int }}$ are both statistically significant and have the signs postulated in hypothesis 3 , which is thus confirmed. However, the explanatory power $r^{2}$ of this model is clearly smaller than the corresponding $\mathrm{r}^{2}=0.899$ of the power of the national civil society (see Tab. 1, model B4). This finding probably mirrors the relative weakness of the international NGOs concerned.

\section{THE JOINT EFFECTS OF THE NATIONAL AND INTERNATIONAL CONSTRAINTS}

With the parameter estimates of the previous Tabs. 1 and 2 it is possible to quantify the constraints

$$
\mathrm{C}_{\mathrm{i}}=\mathrm{E}_{\mathrm{i}} *\left(1-\mathrm{k}_{\mathrm{i}}-\mathrm{c}_{\mathrm{i}} * \mathrm{P}_{\mathrm{i}}\right)
$$

which are given by the national civil society ( $\mathrm{i}=$ nat) and the international NGOs ( $\mathrm{i}=$ int). As mentioned earlier, the chosen $\mathrm{F}_{+}$must comply with both constraints and consequently has to fulfil the inequality

$$
\mathrm{F}_{+} \geq \max \left(\mathrm{C}_{\text {nat }}, \mathrm{C}_{\text {int }}\right)
$$

On the one hand, this expression allows predictions to be made about the future freedom $\mathrm{F}_{+}$. These predictions are less precise but more reliable and robust than the usual forecasts: the constraints which they are based on are given by the power of other interest groups. On the other hand, inequality (14) leads to the additional research question which of the two groups is more important for constraining the governmental decisions about future democratic freedom. The answer depends on the differences with regard to the power of the two groups. According to Fig. 5a, the NGOs are generally not strong enough to really influence governmental decisions. This confirms earlier investigations of Hufbauer et al. (2009: 159), where only $31 \%$ of all international sanctions lead to the intended regime change / democratisation. Conversely, national civil society is much more important, especially if political freedom is high. Only if the political freedom $F_{-} 2011$ and the related power $\mathrm{P}_{\text {nat }}$ of the national civil society are very limited and trade dependency is very high, are international NGOs important enough to constrain governmental policies (see Fig. 5b). However, also in this situation the influence of the NGOs is rather weak. This result is not so unexpected, as many recent trade boycotts had only limited success. 
Georg P. Mueller, Explaining the Policy Constraints of Anti-democratic Regimes by

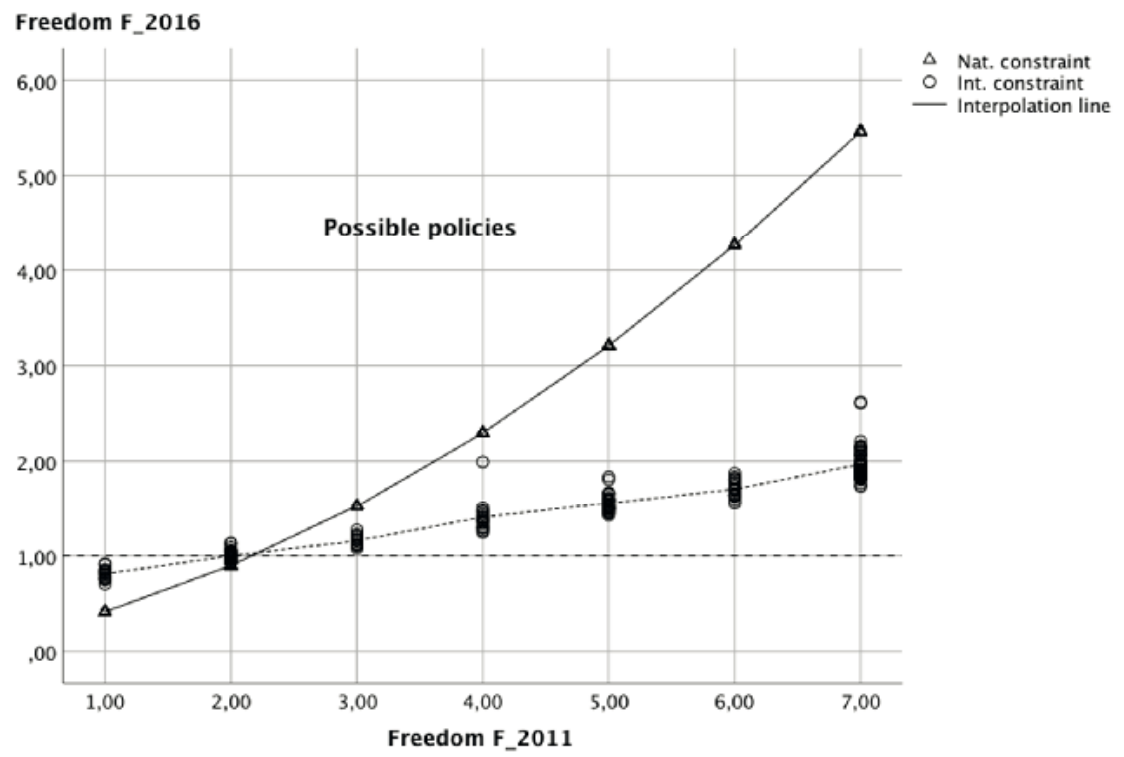

Fig. 5a: A synoptic view of the constraints $C_{\text {nat }}$ and $C_{\text {int }}$ of countries at all levels level of trade dependency TradeDep_2011 ${ }^{8)}$

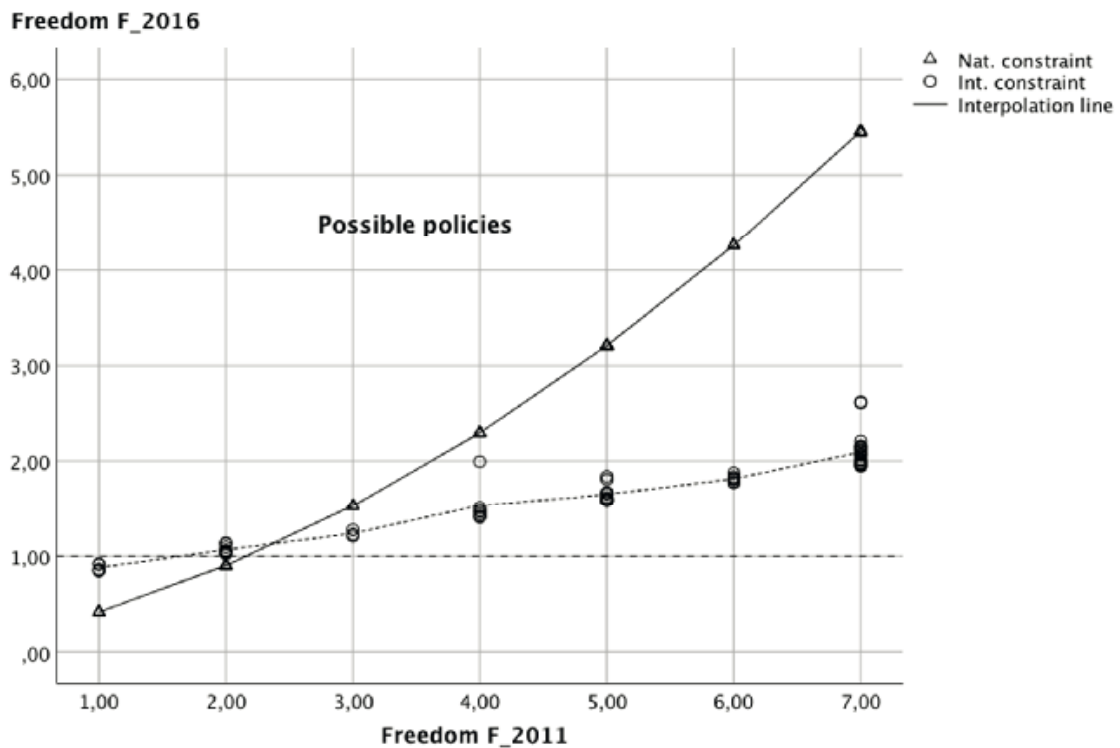

Fig. 5b: A synoptic view of the constraints $C_{\text {nat }}$ and $C_{\text {int }}$ of countries with high trade dependency TradeDep_2011>100 ${ }^{\text {) }}$ 


\section{SUMMARY AND CONCLUSIONS}

This article is a plea to look at possible instead of real behaviour. Sociological analysis generally focuses on the second type of behaviour, which, however, is often difficult to explain: social actors are in many situations irrational, emotional, and have unstable preferences and free will (Frank 2005; Berthoz 2006), which is often neglected in modern sociological analysis (Scheff 1992). Conversely, impossible behaviour constrained by the power and interests of significant others is much easier to model and has a higher reliability. Possible behaviour is complementary to impossible behaviour and consequently shares its analytical advantages - and also some disadvantages:

a) Explanations with the presented constraint model are generally sound and robust: they can only fail if one supposes that significant others do not make use of their power in order to defend their own interests. Typically, regressions describing the behavioural constraints have in terms of the adjusted $r^{2}$ a higher explanatory power than conventional regression models.

b) Forecasts are very reliable, as they typically refer to impossible scenarios. However, the complementary forecasts about possible behaviour are often vague and imprecise. Thus, it is important to explore all constraints, e.g. not only the lower boundaries of possible political freedom but also the upper ones, which has not been done for this article.

c) Assessments of the relative weights of different constraints and their supporters are important by-products for further analyses. In strategic terms, such weights allow for assessment of the power gains which are necessary in order to turn less important groups into key players of the political game. In analytic terms, they help to assess the consequences from trends in the power distribution on the future importance of the concerned political actors.

This article illustrates the aforementioned advantages of analysing possible instead of real behaviour for the case of the impairment of political freedom by antidemocratic regimes. Because of the general nature of the key concepts, i.e. the power $\mathrm{P}_{\mathrm{i}}$ of the different groups and their expectations $\mathrm{E}_{\mathrm{i}}$, the method of analysing constraints by sequential regressions can easily be applied to other political domains like social or welfare policy, as shown by the author in previous research (see Mueller 2003, 2006). The availability of a sufficient number of appropriate cases is, however, important for the successful use of the proposed methodology. Since the final regression equation $f_{n}(X)$ for the parameter estimation is calculated with ca. $10 \%$ of the original data points (see section 3), a lot of data are intentionally "wasted" so that at least 100 observations are required. Moreover, it should be plausible by the intentions of the analysed social actors that the mentioned $10 \%$ of the original values are sufficiently close to their behavioural constraints. 


\section{APPENDIX: GLOSSARY OF MATHEMATICAL TERMS}

$b_{i}$ : $\quad$ Parameter describing the basic expectation of group $i$, if $F=F_{\min }$. See equation (1a).

$c_{i}$ : $\quad$ Parameter describing the effect of the power $\mathrm{P}_{i}$ of group $\mathrm{i}$ on its tolerance $\mathrm{T}_{\mathrm{i}}$ (see equation (3)).

$\mathrm{C}_{\mathrm{i}}$ : $\quad$ Constraint of possible governmental policies, set by the power of group $\mathrm{i}$.

$\mathrm{D}_{\mathrm{i}}$ : $\quad$ Rel. deviance of the governmental policy from the expectation $\mathrm{E}_{\mathrm{i}}$ of group $i$.

$\Delta: \quad$ Difference between the current freedom $\mathrm{F}$ and the expectation $\mathrm{E}_{\mathrm{i}}$ about freedom $\mathrm{F}_{+}$at a future point in time.

$\mathrm{E}_{\mathrm{i}}$ : $\quad$ Expectation of group $\mathrm{i}$ about the freedom $\mathrm{F}_{+}$at a future point in time.

F: $\quad$ Freedom at the baseline time-point.

$\mathrm{F}_{+}$: $\quad$ Freedom at a future point in time.

F_2011: Political freedom in $2011=$ Operationalisation of $\mathrm{F}$ and $\mathrm{P}_{\text {nat }}$.

F_2016: Political freedom in $2016=$ Operationalisation of $F_{+}$.

$\mathrm{F}_{\max }$ : $\quad$ Highest possible value of $\mathrm{F}$ and $\mathrm{F}_{+}$, given by the operationalisations of $\mathrm{F}$ and $\mathrm{F}_{+}$.

$\mathrm{F}_{\text {min }}$ : $\quad$ Lowest possible value of $\mathrm{F}$ and $\mathrm{F}_{+}$, given by the operationalisations of $\mathrm{F}$ and $\mathrm{F}_{+}$.

int: $\quad$ Group $\mathrm{i}=$ International NGOs for the promotion of political freedom.

$\mathrm{k}_{\mathrm{i}}$ : $\quad$ Parameter describing the effect of the power $\mathrm{P}_{\mathrm{i}}$ of group $\mathrm{i}$ on its tolerance $\mathrm{T}_{\mathrm{i}}$ (see equation (3)).

max: $\quad$ Maximum.

nat: $\quad$ Group $i=$ National civil society.

$\mathrm{P}_{\mathrm{i}}$ : $\quad$ Power of group $\mathrm{i}$.

$\mathrm{T}_{\mathrm{i}}$ : $\quad$ Tolerance of group $\mathrm{i}$ with regard to deviations from its expectation $\mathrm{E}_{\mathrm{i}}$.

TradDep_2011: Trade dependency in $2011=$ Operationalization of $\mathrm{P}_{\text {int }}$.

\section{NOTES}

1 From equation (4) follows for any $\mathrm{F}_{+}$on the constraint-line $C_{i}$ between possible and impossible policies: $\left(\mathrm{E}_{\mathrm{i}}-\mathrm{F}_{+}\right) / \mathrm{E}_{\mathrm{i}}=\mathrm{k}_{\mathrm{i}}+\mathrm{c}_{\mathrm{i}} * \mathrm{P}_{\mathrm{i}}$. Thus $\left(\mathrm{E}_{\mathrm{i}}-\mathrm{F}_{+}\right)=\mathrm{E}_{\mathrm{i}} *\left(\mathrm{k}_{\mathrm{i}}+\mathrm{c}_{\mathrm{i}} * \mathrm{P}_{\mathrm{i}}\right)$ and $-\left(\mathrm{E}_{\mathrm{i}}-\mathrm{F}_{+}\right)=-\mathrm{E}_{\mathrm{i}} *\left(\mathrm{k}_{\mathrm{i}}+\mathrm{c}_{\mathrm{i}} * \mathrm{P}_{\mathrm{i}}\right)$. Consequently $\mathrm{F}_{+}=\mathrm{E}_{\mathrm{i}}-\mathrm{E}_{\mathrm{i}} *\left(\mathrm{k}_{\mathrm{i}}+\mathrm{c}_{\mathrm{i}} * \mathrm{P}_{\mathrm{i}}\right)=\mathrm{E}_{\mathrm{i}} *\left(1-\left(\mathrm{k}_{\mathrm{i}}+\mathrm{c}_{\mathrm{i}} * \mathrm{P}_{\mathrm{i}}\right)\right)$ $=E_{i} *\left(l-k_{i}-c_{i} * P_{i}\right)=C_{i}$, since $\mathrm{F}_{+}$was assumed to be on the constraint line $\mathrm{C}_{\mathrm{i}}$.

2 www.freedomhouse.org/report/freedom-world/freedom-world-2017 $\rightarrow$ download "FIW 2017 Data" $\rightarrow$ open folder "FIW2017_Data" $\rightarrow$ open EXCEL-file FH_Country_and_ Territory_Ratings_and_Statuses_1972-2016 (accessed on March 7, 2017).

3 For details of the rather complex operationalisation, see the original description of Freedom House in https://freedomhouse.org/report/methodology-freedom-world-2018.

4 In terms of the iteratively reweighted least squares procedure, the observations with negative residuals are assigned the weight 0 , whereas the other observations keep the original weight 1 . 
5 In classical test theory $5 \%$ is the "weakest" limiting probability for rare events, which is often used to reject null hypotheses.

6 Fat circular markers in this scatterplot represent multiple entries, i.e. several countries with identical values for F_2011 and D.

7 The parameters of the regression line in Fig. $4 \mathrm{~b}$ are identical to the parameters of the model B1 in Tab. 1.

8 By definition F_2016 = 1 is the minimum possible level of political freedom.

\section{REFERENCES}

Andersen, Robert. 2008. Modern Methods for Robust Regression. Sage: Los Angeles. https://doi.org/10.4135/9781412985109

Berthoz, Alain. 2006. Emotion and Reason: The Cognitive Neuroscience of Decision Making. Oxford Unversity Press: Oxford.

Cleveland, Sarah. 2015. Human Rights Sanctions and International Trade: A Theory of Compatibility. In: M. P. Malloy (ed.) Economic Sanctions, vol. 2, chap. 2. Edward Elgar Publishing: Cheltenham.

Davies, James. 1972. Toward a Theory of Revolution. In: I. Feierabend et al. (eds.) Anger, Violence, and Politics, chap. 4. Prentice-Hall: Englewood Cliffs.

Earman, John. 1986. A Primer on Determinism. Reidel Publishing: Dordrecht.

Frank, Robert. 2005. Departures from Rational Choice: With and Without Regret. In: F. Parisi and V. Smith (eds.) The Law and Economics of Irrational Behavior, chap. 1. Stanford University Press: Stanford.

Freedom House. 2017. Freedom in the World 2017. (www.freedomhouse.org/report/ freedom-world/freedom-world-2017) (accessed on March 7, 2017).

Giannone, Diego. 2010. Political and Ideological Aspects in the Measurement of Democracy: The Freedom House Case. Democratization 17(1): 68-97. https://doi. org/10.1080/13510340903453716

Gurr, Robert. 2010. Why Men Rebel (40th anniversary edition). Paradigm Publishers: Boulder.

Hibbs, Douglas. 1973. Mass Political Violence: A Cross-National Causal Analysis. John Wiley: London.

Hufbauer, Gary, et al. 2009. Economic Sanctions Reconsidered (3rd edition). Peter G. Peterson Institute for International Economics: Washington DC.

Hughes, Brian M. 2018. Psychology in Crisis. Palgrave: London.

Mueller, Georg P. 2003. Zum prognostischen Potenzial von wohlfahrtsstaatlichen Handlungsspielräumen. (The prognostic capabilities of the action-space concept for research about the welfare state) In: J. Allmendinger (ed.), Entstaatlichung und Soziale Sicherheit, vol. 3. Leske + Budrich: Opladen.

Mueller, Georg P. 2006. Die Grenzen der ökonomischen Ungleichheit: Ein spieltheoretischer Erklärungsansatz (The limits of economic inequality: a game theoretical approach). In: K.-S. Rehberg (ed.). Soziale Ungleichheit, Kulturelle Unterschiede, vol. 3 (CD-ROM), pp. 2158-2169. Campus Verlag: Frankfurt a.M.

Mueller, Georg P. 2012. On the Limits and Possibilities of Causal Explanation with Game Theoretical Models: The Case of Two Party Competition. ASK 21: 69-85. 
Rubin, Donald. 1983. Iteratively Reweighted Least Squares. In: S. Kotz et al. (eds.) Encyclopedia of Statistical Sciences, vol. 4, pp. 272 ff. John Wiley: New York.

Scheff, Thomas. 1992. Rationality and Emotion. In: J. Coleman and Th. Fararo (eds.). Rational Choice Theory: Advocacy and Critique, chap. 5. Sage Publications: Newbury Park.

Schmidt, Stefan. 2017. Replication. In: M. Makel and J. Plucker (eds.). Toward a More Perfect Psychology, chap. 14. American Psychological Association: Washington DC. Schueler, G. F. 2003. Reasons and Purposes: Human Rationality and the Teleological Explanation of Action. Clarendon Press: Oxford.

Stout, Rowland. 1996. Things That Happen Because They Should: A Teleological Approach to Action. Oxford University Press: Oxford. https://doi.org/10.1093/ acprof:oso/9780198240631.001.0001

World Bank. 2019. Trade (\% of GDP). (https//data.worldbank.org/indicator/ NE.TRD:GNFS.ZS) (accessed on February 28, 2019).

Georg P. Mueller is a retired senior lecturer at the Faculty of Economics and Social Sciences of the University of Fribourg, Switzerland. He has a Ph. D. in sociology from the University of Zurich. His research interests include the mathematical modelling of social processes, social research methods, and the construction of social indicators for the monitoring of social problems and policies. 
